\title{
Wnt Regulation of Progenitor Maturation in the Cortex Depends on Shh or Fibroblast Growth Factor 2
}

\author{
Jane Viti, Alexandra Gulacsi, and Laura Lillien \\ Department of Neurobiology and Pittsburgh Cancer Institute, University of Pittsburgh School of Medicine, Pittsburgh, Pennsylvania 15261
}

In the embryonic mouse cerebral cortex, progenitors in the ventricular zone (VZ) undergo a developmental change between embryonic day 13 (E13) and E15. This results in the generation of a secondary proliferative population and the appearance of a second germinal layer, the subventricular zone (SVZ). We have shown previously that bone morphogenetic proteins (BMPs) and fibroblast growth factor 2 (FGF2) act antagonistically to regulate the development of a subset of SVZ progenitors that normally express a high level of epidermal growth factor (EGF) receptors and divide in response to EGF. In the present study, we show that Wnt 7a, Wnt 7b, and Sonic hedgehog (Shh) promote progenitor maturation in explant cultures, as reported for FGF2. Wnts $7 \mathrm{a}$ and $7 \mathrm{~b}$ also stimulate the proliferation of neurogenic progenitors and increase the number of cells that can generate primary neurospheres. To determine whether Wnts, FGF2, and Shh act independently or in a common pathway, each factor was inhibited in cortical explants. This revealed that endogenous Wnts, FGF2, and Shh normally contribute to progenitor maturation. Moreover, Wnt 7a depends on FGF2 or Shh to promote maturation but not proliferation. Maturation induced by blocking BMPs also depends on Shh. In contrast, FGF2 promotes maturation by a Shh-independent mechanism. In vivo, progenitors infected with a Wnt 7a retrovirus at E10.5 were found preferentially in the SVZ at E16.5. These findings suggest that Wnts depend on Shh or FGF2 to promote progenitor maturation to an SVZ state in the embryonic cortex.

Key words: cortex; epidermal growth factor receptor; Wnt; Shh; fibroblast growth factor; subventricular zone; bone morphogenetic protein

\section{Introduction}

The cerebral cortex develops from two germinal layers: the ventricular zone (VZ), a pseudostratified epithelium that lines the lateral ventricles, and the subventricular zone (SVZ), which begins to develop at approximately embryonic day 13 (E13) in mice (Boulder Committee, 1970). VZ progenitors are thought to give rise to SVZ progenitors (Takahashi et al., 1995; Burrows et al., 1997; Haydar et al., 2000), but the mechanisms underlying this transition are not well defined.

Previous work suggested that the transition from VZ to SVZ was associated with an increase in the expression of epidermal growth factor (EGF) receptors (EGFRs) (Seroogy et al., 1995; Eagleson et al., 1996; Kornblum et al., 1997), which confers mitotic responsiveness to EGF-family ligands (Burrows et al., 1997). The EGF-responsive population represents a subset of the SVZ and is itself heterogeneous, including stem cells and more restricted progenitors. Maturation to an EGF-responsive state is regulated by positive and negative extrinsic factors (Lillien and Raphael, 2000). For example, bone morphogenetic proteins (BMPs) inhibit this change in part by antagonizing the expression or availability of a factor that promotes progenitor maturation.

Received Jan. 20, 2003; revised April 14, 2003; accepted April 16, 2003.

This work was supported by National Institutes of Health Grant NS-38306. We thank Jennifer Phillips and Adam Czaikowski for technical assistance.

Correspondence should be addressed to Laura Lillien, Department of Neurobiology and Pittsburgh Cancer Institute, University of Pittsburgh School of Medicine, W1454 Biomedical Science Tower, Pittsburgh, PA 15261. E-mail: lillien+@pitt.edu.

Copyright $\odot 2003$ Society for Neuroscience $\quad$ 0270-6474/03/235919-09\$15.00/0
Although fibroblast growth factor 2 (FGF2) was suggested as a candidate for a maturation-promoting signal, we did not rule out the contribution of additional factors.

In Drosophila, the BMP homolog dpp inhibits the expression of Wg (Penton and Hoffman, 1996), raising the possibility that Wnts could promote progenitor maturation in the vertebrate CNS. Wnt 7a is expressed in the germinal layers of the embryonic mouse cortex (Grove et al., 1998), as are several Frizzled (Fz) receptors (Kim et al., 2001b), which mediate Wnt signaling (for review, see Wodarz and Nusse, 1998). Wnt 7b is expressed in the cortical plate, particularly by deep-layer neurons (Rubenstein et al., 1999; Kim et al., 2001a). The functions of Wnt 7a and Wnt 7b in the developing cortex are not known, but other Wnt family members stimulate proliferation in the CNS (Lee et al., 2000; Fukuchi-Shimogori and Grove, 2001; Megason and McMahon, 2002), and Wnts regulate stem cells in other tissues (Austin et al., 1997; Korinek et al., 1998). Several observations also suggest Shh as a candidate for a maturation-promoting signal. For example, BMPs interact antagonistically with Shh in cultures of neural progenitors (Zhu et al., 1999), EGFR expression is induced by $\mathrm{Hh}$ in Drosophila (Huang et al., 1998), cortical progenitors express receptors for Shh (Zhu et al., 1999; Dahmane et al., 2001), and Shh is expressed in the late embryonic cortex (Dahmane et al., 2001).

To address the contribution of Wnts, Shh, and FGF2 to progenitor maturation, exogenous factors were added to explants, and signaling by these factors was blocked in explants. Wnt $7 \mathrm{a}$ expression was also enhanced in vivo with a retrovirus. In other 
tissues, some effects of Wnts depend on FGFs or Shh (Yang and Niswander, 1995; McGrew et al., 1997; Kengaku et al., 1998; Domingos et al., 2001; Kawakami et al., 2001). We therefore examined interactions between Wnt 7a, FGF2, and Shh to determine whether they act independently or in a common pathway to regulate progenitor maturation.

\section{Materials and Methods}

Retroviruses. Wnt 7a (human), 7b (mouse), and 3a (mouse) coding sequences (Upstate Biotechnology, Lake Placid, NY) were cloned into the pLIGnp retroviral vector. pLIGnp was made from pLIGns (Lillien, 1995) by replacing the $S n a \mathrm{~B} 1$ site with a $P a c \mathrm{I}$ site. This retroviral vector also contains $\beta$-geo (lacZ plus neomycin phosphotransferase) (Friedrich and Soriano, 1991), allowing selection and identification of transfected/infected cells. For controls, we used a virus encoding lacZ and alkaline phosphatase (IZAP) (Burrows et al., 1997). Virus encoding dnBMPR1B (ten Dijke et al., 1994; Zou and Niswander, 1996) was described previously (Lillien and Raphael, 2000). Viruses were made in the $\psi 2$ packaging line, as described previously (Cepko et al., 1993). Viruses with titers of $0.9 \times 10^{7}$ to $1.5 \times 10^{7} \mathrm{cfu} / \mathrm{ml}$ were used in vivo and in vitro. The Wnt cDNAs included HA tags. To confirm that appropriate proteins were expressed, lysates of infected 3T3 cells were prepared and Western blots were probed with anti-HA antibody (Boehringer Mannheim, Indianapolis, IN; data not shown).

Cultures. For explant cultures, explants of embryonic cortex were prepared from timed-pregnant CD1 mice (Charles River Laboratories, Wilmington, MA). Developmental stage was determined from crown-torump length and examination of external features (Theiler, 1972). Brains were dissected in HBSS (Invitrogen, Bethesda, MD), and two to five explants of dorsolateral cortex were placed on a Nucleopore filter (13 $\mathrm{mm}, 0.2 \mu \mathrm{m}$ pore; Corning, Corning, NY). Progenitor cells were infected with either a control virus expressing $\beta$-galactosidase ( $\beta$-gal) (IZAP; Burrows et al., 1997) or a virus coexpressing $\beta$-galactosidase and Wnt 3a, 7a, 7b, or dnBMPR1B (Lillien and Raphael, 2000). Cells were infected by adding 20-30 $\mu \mathrm{l}$ of medium containing virus to the tops of the filters. This results in the selective infection of dividing cells at the ventricular surface (Burrows et al., 1997). Growth factors, antibodies, recombinant mouse Fz8-Fc (R\&D Systems, Minneapolis, MN), IgG-Fc (R\&D Systems), or cyclopamine (Toronto Research Chemicals, Toronto, Canada) were added daily, beginning $1 \mathrm{~d}$ after infection. The antibodies included anti-Shh culture supernatant (5E1) (Ericson et al., 1996), used at dilutions of 1:5 to 1:4 (Developmental Studies Hybridoma Bank; DSHB), mouse anti-FGF2 (10-15 $\mu \mathrm{g} / \mathrm{ml}$; Upstate Biotechnology), and rabbit anti-FGF2 (10-50 $\mu \mathrm{g} / \mathrm{ml}$; R\&D Systems). For controls, culture supernatant containing mouse anti-PAX6 (DSHB), rabbit IgG (R\&D Systems), or mouse IgG (R\&D Systems) was added at the same concentrations as the relevant antibody or culture supernatant. Growth factors included recombinant FGF2, Shh-N terminal peptide, and BMP4 (all from R\&D Systems). After a total of 4-6 d in culture, some explants were fixed for immunocytochemistry, and others were dissociated (see below). Dissociated cells were either stained with antibodies (see below) or cultured in EGF or FGF2 (R\&D Systems) to assay for the presence of cells that can generate "neurospheres," a characteristic of stem cells (Reynolds and Weiss, 1992). Explants were dissociated with 0.4\% trypsin (Sigma, St. Louis, MO) for $15 \mathrm{~min}$ at $35^{\circ} \mathrm{C}$, triturated, and cultured on uncoated tissue culture dishes ( 24 well plate, $5 \times 10^{4}$ cells per well; Corning) in serum-free medium (Bottenstein and Sato, 1979) containing $1-10 \mathrm{ng} / \mathrm{ml}$ EGF or $10 \mathrm{ng} / \mathrm{ml} \mathrm{FGF2} \mathrm{(R \& D} \mathrm{Systems)} \mathrm{for} 10 \mathrm{~d}$. Medium (0.2 ml) containing fresh growth factors was added every $4 \mathrm{~d}$. The number of infected cells per culture was counted at the time cells were plated. The number of neurospheres per well was counted after $10 \mathrm{~d}$, and the number of neurospheres derived from infected cells was determined by staining for $\beta$-galactosidase. We could estimate the proportion of infected cells that generated a neurosphere by dividing the number of $\beta$-gal-positive neurospheres per well by the number of $\beta$-gal-positive cells cultured per well initially. To passage neurospheres, they were treated with trypsin $(0.05 \%)$-EDTA $(0.5 \mathrm{~mm})$ (Invitrogen) for $5 \mathrm{~min}$ at $35^{\circ} \mathrm{C}$, triturated in egg white trypsin inhibitor and deoxyribonuclease I ( $50 \mu \mathrm{g} / \mathrm{ml}$ of each; Sig- ma), and plated at $1 \times 10^{3}$ to $4 \times 10^{3}$ cells per well ( 24 well culture plate) as described above for primary neurosphere cultures. All culture experiments were performed at least three times, using two to five explants per condition per experiment. Data are expressed as mean \pm SEM. Statistical differences were determined by $t$ tests using StatView software and were considered significant at a value of $p<0.05$.

5-bromo-4-chloro-3-indolyl- $\beta$-D-galactopyranoside histochemistry and immunocytochemistry. For 5-bromo-4-chloro-3-indolyl- $\beta$-D-galactopyranoside (X-gal) histochemistry, brains were fixed in $4 \%$ paraformaldehyde (PFA) in $0.1 \mathrm{~m}$ phosphate buffer (pH 7.4) or 3\% PIPES buffer for $2 \mathrm{hr}$ at $4^{\circ} \mathrm{C}$, and cultures were fixed in $0.5 \%$ glutaraldehyde in PBS for 7.5 min at room temperature. For immunocytochemistry, explants either were dissociated, allowed to attach to poly-D-lysine-coated slides, and stained $1 \mathrm{hr}$ later or were fixed in $4 \%$ PFA for $2 \mathrm{hr}$ at $4^{\circ} \mathrm{C}$, rinsed in PBS, cryoprotected in graded sucrose (10-30\%), frozen, and sectioned at 20 $\mu \mathrm{m}$. Sections were blocked in PBS containing 10\% FBS (Invitrogen) and $0.1 \%$ Triton X-100. Primary antibodies were applied overnight in block at $4^{\circ} \mathrm{C}$. To stain cells acutely after dissociation, cells on poly-D-lysinecoated slides were fixed in $4 \%$ PFA for $10 \mathrm{~min}$ at room temperature, rinsed, and blocked, then primary antibodies were applied for $1 \mathrm{hr}$ at room temperature. Primary antibodies included rabbit anti- $\beta$ galactosidase (1:1000; Cortex Biochem, San Leandro, CA), mouse anti$\beta$-galactosidase (1:200; Promega, Madison, WI), mouse anti-MAP2 (1:200; Sigma), mouse anti-S-100 $\beta$ (1:400; Sigma), mouse anti-GFAP (1:400; Sigma), and sheep anti-EGFR (1:50; Upstate Biotechnology). Antibodies were visualized with donkey anti-rabbit $\mathrm{Cy} 3$ or Cy2, anti-sheep $\mathrm{Cy} 3$, or anti-mouse Cy2 (Jackson ImmunoResearch, West Grove, PA) applied for 30-120 min at room temperature. Sections and dissociated cells were examined with a Leica DMR microscope (Leica, Nussloch, Germany) using bright-field and fluorescence optics. Images were captured using a Sensys digital camera and IPLab and Photoshop software. At least 100 infected cells per condition were counted for each experiment, and experiments were repeated at least three times. Data are represented as mean \pm SEM. Differences were considered significant at a value of $p<0.05$ using $t$ tests and StatView software.

Infections in vivo. To infect telencephalic progenitors in vivo, viruses were injected into lateral ventricles at E14.5 or E10.5 as described previously (Caric et al., 2001). Briefly, for E14.5 embryos, after midline laparotomy, one uterine horn was exposed, and a fiber-optic light was placed against the uterine wall to visualize the lateral ventricle. Virus $(\sim 1 \mu \mathrm{l}$, containing $80 \mu \mathrm{g} / \mathrm{ml}$ polybrene, $0.025 \%$ fast green, and $10 \%$ FBS) was injected through the uterine wall into the lateral ventricle with a beveled glass micropipette. Three to four embryos per horn were injected, the uterine horn was replaced, and the dam was sutured. Three to $4 \mathrm{~d}$ later, the injected embryos were removed, and the brains were fixed for $2 \mathrm{hr}$ in $4 \%$ PFA (in 3\% PIPES buffer) at $4^{\circ} \mathrm{C}$. Brains were then rinsed in PBS and stained as whole mounts with X-gal (Molecular Probes, Eugene, OR). After overnight incubation in $\mathrm{X}$-gal at $37^{\circ} \mathrm{C}$, brains were rinsed, cryoprotected in graded sucrose (10-30\%), and frozen. For infections at E10.5, one uterine horn was exposed, and the lateral ventricles of the embryos were visualized using an ultrasound backscatter probe (Humphrey Systems, Dublin, CA) (Olsson et al., 1997). Virus was injected into the lateral ventricle with a beveled glass micropipette via a mineral oil-filled syringe attached to a manual microsyringe pump (Stoelting, Kiel, WI). Three to four embryos were injected per litter, the uterus was replaced, and the dam was sutured. Six days later, the embryos were collected and processed as described above.

Data analysis in vivo. For analysis of the distribution of infected cells, $50 \mu \mathrm{m}$ frozen sections were collected and counterstained with DAPI (Molecular Probes). The location of X-gal-labeled cells was analyzed with a Leica DMR microscope and bright-field optics. All labeled cells in all sections were counted. To analyze the laminar distribution of infected cells in the cortex, the cerebral wall was divided into six layers, as follows: ventricular zone (VZ), subventricular zone (SVZ), intermediate zone (IZ), subplate/white matter, cortical plate, and marginal zone. The medial, dorsolateral, and lateral regions of the cortex were included in the analysis because they normally express Wnt 7a (Grove et al., 1998). For infections at E14.5, we analyzed the locations of 1156 cells in the cortices of five brains infected with control virus and 473 cells in the cortices of 
five brains infected with Wnt7a. For infections at E10.5, we analyzed the locations of 4424 cells in cortices of three brains infected with control virus and 988 cells in cortices of seven brains infected with Wnt 7a virus. For analysis of differences in the laminar distribution of infected cells, the proportion of infected cells in a specific layer was determined for each brain, and the two viruses were compared by use of a Mann-Whitney test. Data are expressed as mean \pm SEM. Values of $p<0.05$ were considered significant. One of the brains infected with control virus at E10.5 was much more heavily infected than any of the other brains. It was included in the analysis because compared with other control infected brains, the laminar distribution of the infected cells was not significantly different. For infections at E14.5, one of the control infected brains was also more heavily infected than the others. Again, the laminar distribution of infected cells was independent of infection frequency compared with other brains infected with control virus. Infected cells were also found outside the cortex (i.e., olfactory bulb, striatum, hippocampus). The regional distributions of cells infected with the two viruses were also compared, but we did not observe any significant differences (data not shown). Note that the data for control infected brains were obtained from animals included in a study published previously (Caric et al., 2001).

\section{Results}

\section{Wnts stimulate proliferation in vitro}

To analyze the effects of Wnts on progenitor cells, we used explants of dorsolateral embryonic mouse cortex, which closely approximate the developing cortex in vivo (Burrows et al., 1997). Explants were infected with a retrovirus that transduces a Wnt
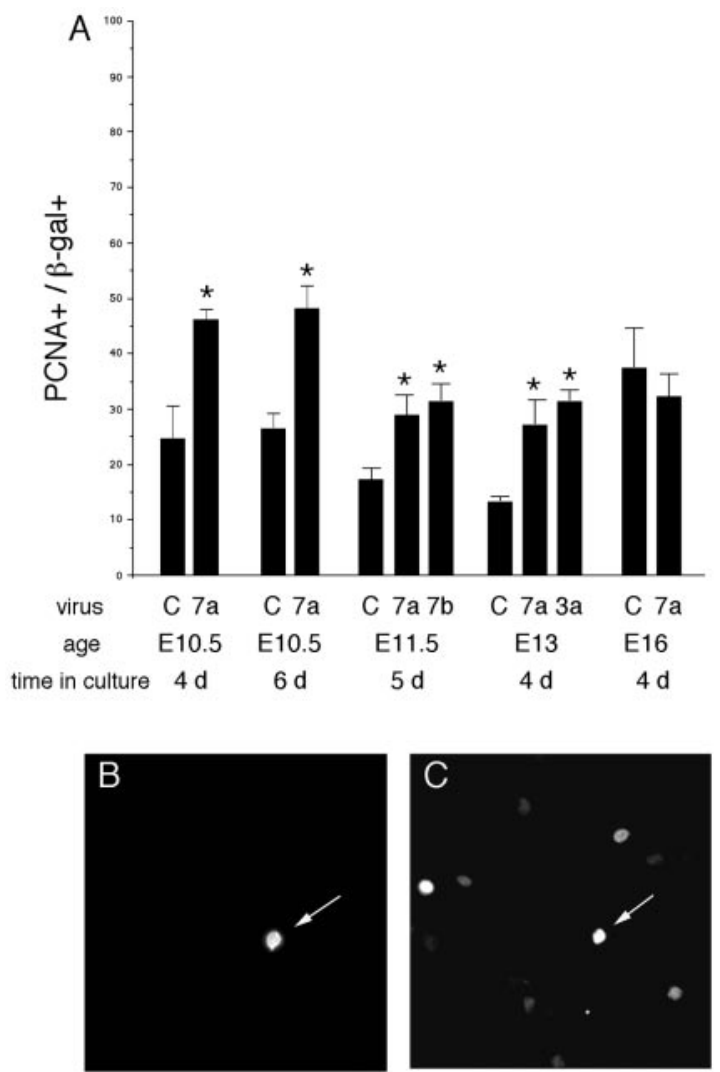

Figure 1. Wnts stimulate proliferation in vitro. A, Explants of E10.5-E16 dorsolateral cortex were infected with control or Wnt 7a, 7b, or 3a viruses. Four to $6 \mathrm{~d}$ later, explants were dissociated and cells stained with anti- $\beta$-gal ( $B$ ) to identify infected cells and anti-PCNA ( $C$ ) to identify dividing cells. The proportion of $\beta$-gal-positive cells that express PCNA was counted $(A)$. Note that Wnts stimulate proliferation in E10.5-E13 but not E16 cortical explants. B, C, A Wnt 7ainfected cell expresses the viral marker $\beta$-gal ( $B$, arrow) and PCNA (C, arrow). ${ }^{*} p<0.05$ relative to control virus. and the histochemical marker $\beta$-galactosidase or a control virus that transduces only the marker. Proliferation of infected cells was assessed 4-6 d later by staining for proliferating cell nuclear antigen (PCNA), a marker of dividing cells, or by incorporation of bromodeoxyuridine (BrdU). Wnt 7a increased the proportion of PCNA-positive cells after infection of E10.5-E13.5 mouse cortex (Fig. 1). Wnt 7a also increased the incorporation of BrdU. Explants of E10.5 mouse cortex were cultured for $4 \mathrm{~d}$, with BrdU added for the last $24 \mathrm{hr}$. Of the cells infected with Wnt 7a, $74.3 \pm$ $4.6 \%$ incorporated BrdU, compared with $27.7 \pm 4.1 \%$ of control infected cells $(p=0.04)$. Increased proliferation was also observed with viruses transducing two other members of the Wnt family, Wnt 7b and Wnt 3a (Fig. 1). The Wnt inhibitor mFz8-Fc, however, did not alter proliferation among control infected cells $(21 \pm 3.8$ vs $24 \pm 3.2 \%$, E11.5 plus $5 \mathrm{~d} ; n=6)$. This could reflect the presence of redundant mitogenic signals. In contrast to its effects in E10.5-E13.5 cultures, Wnt 7a did not enhance proliferation when progenitors were infected later, at E16 (Fig. 1). This is consistent with the decline in Fz expression among cortical progenitor cells by E17.5 (Kim et al., 2001b).

\section{Wnt 7a reversibly inhibits neuronal differentiation}

In addition to stimulating proliferation, Wnt 7a inhibited expression of the early neuronal marker TuJ1 $6 \mathrm{~d}$ after infection at E10.5 (Fig. 2). A decline in the proportion of TuJ1-positive cells was also observed with Wnt $3 \mathrm{a}$ and Wnt $7 \mathrm{~b}$ viruses (data not shown). Although Wnts inhibited neuronal differentiation, they did not induce astrocytes, identified by S- $100 \beta$ or GFAP expression, or oligodendrocyte lineage cells, identified by NG2 or RIP expression (data not shown). To confirm that Wnt 7a-infected progenitors were still able to differentiate into neurons, cell-cell interactions were disrupted by dissociating explants and culturing cells as a monolayer. One day later, TuJ1 expression among Wnt $7 \mathrm{a}$-infected cells rose to levels seen in control infected explants (Fig. 2), confirming that Wnt 7a-infected progenitors were still able to generate neurons. This suggests that Wnts stimulate the

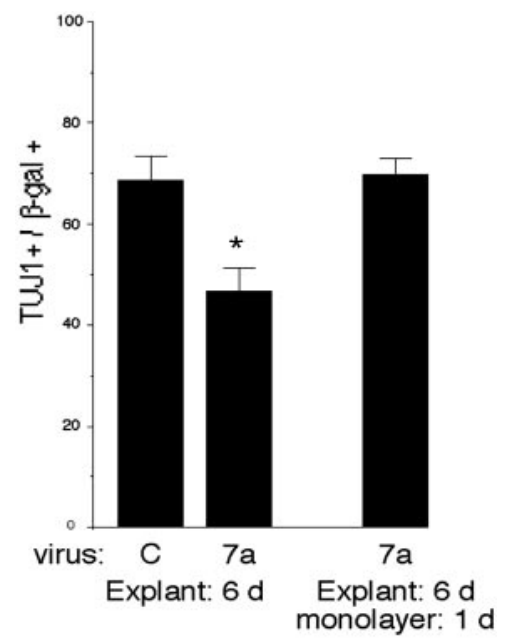

Figure 2. Wnts inhibit neuronal differentiation reversibly. Cortical explants were infected with control or Wnt 7a virus at E10.5 and cultured for $6 \mathrm{~d}$. Explants were then dissociated and stained for expression of the early neuronal marker TuJ1, or cells were cultured as a monolayer to reduce cell-to-cell signaling and promote differentiation. After $1 \mathrm{~d}$ in monolayer culture, cells were stained with anti-TuJ1 and anti- $\beta$-gal. The proportion of neurons among Wnt $7 \mathrm{a}$-infected cells was reduced after $6 \mathrm{~d}$ in explant culture compared with control infected cells but rose to the level seen in control infected explant cultures when allowed to differentiate for $1 \mathrm{~d}$ in monolayer culture. This suggests that Wnts reversibly inhibit the differentiation of progenitors that are competent to produce neurons. ${ }^{*} p \leq 0.04$ comparing Wnt 7a with control virus. 

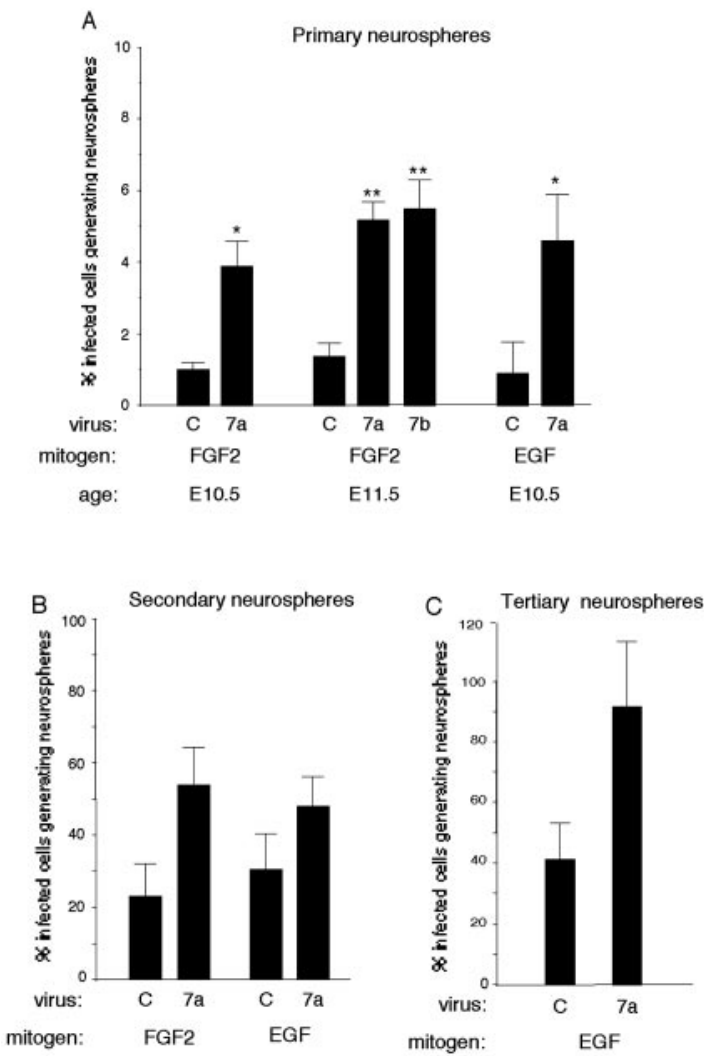

Figure 3. Wnt effects on stem cells. A, Explants of E10.5-E11.5 cortex were infected with control, Wnt 7a, or Wnt 7b virus. After 5-6 d, explants were dissociated and grown under conditions that generate neurospheres with the mitogen FGF2 $(10 \mathrm{ng} / \mathrm{ml})$ or EGF $(1 \mathrm{ng} / \mathrm{ml})$. Ten days later, the proportion of neurospheres derived from infected cells was compared. More primary neurospheres are generated from Wnt 7a- or Wnt $7 b$-infected cells than control infected cells. B, C, Primary neurospheres were passaged, and the proportion of infected cells that generated secondary and tertiary neurospheres was determined. Although Wnt $7 \mathrm{a}$ tended to increase secondary $(B)$ and tertiary $(C)$ neurospheres compared with control infected cultures, the differences were not significant. ${ }^{*} p \leq 0.04$ relative to control virus; ${ }^{* *} p<0.004$ relative to control virus.

proliferation and delay the differentiation of progenitors that are competent to produce neurons.

\section{Wnt effects on stem cells}

Because Wnts stimulated proliferation and delayed differentiation, we wondered whether they also affected stem cells. Stem cells represent a very small proportion of the progenitors in the embryonic cortex. They can be distinguished by their ability to divide to generate a neurosphere that can produce neuronal and glial progeny and additional stem cells. At least two types of stem cells have been identified. Before E14, stem cells are responsive to FGF2 but not EGF. Stem cells become EGF-responsive 1-2 d later as a consequence of increased EGFR expression (Burrows et al., 1997).

At an early embryonic time (E10.5-E11.5), more Wnt 7a- and Wnt $7 \mathrm{~b}$-infected progenitors formed primary neurospheres than control infected cells when FGF2 was used as the stem cell mitogen (Fig. 3A). In the absence of exogenous FGF2, Wnt 7a- and $7 \mathrm{~b}$-infected cultures did not generate neurospheres (data not shown), suggesting that Wnts alone do not stimulate the proliferation of stem cells or that Wnts are not effective mitogens for dissociated stem cells in the absence of appropriate extracellular matrix molecules (Wodarz and Nusse, 1998).

The proportion of EGF-generated primary neurospheres was
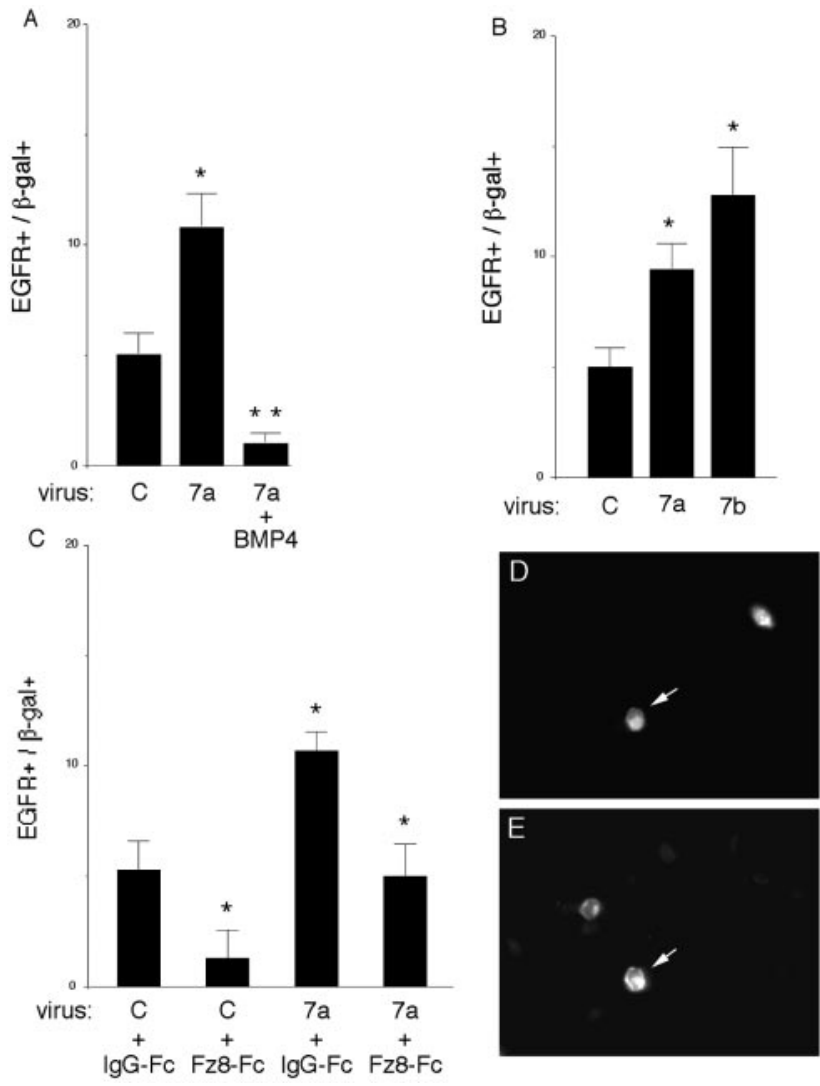

Figure 4. EGFR expression is modulated by Wnts and BMP4. A, Wnt 7a virus increases the proportion of cells that express a high level of EGFRs in E10.5 explants cultured for $5 \mathrm{~d}$. Explants were dissociated and stained with anti- $\beta$-gal $(D)$ to identify infected cells and anti-EGFR $(E)$ to identify cells that express a high level of EGFRs. The effect of Wnt 7a on EGFR expression is inhibited by BMP4 (10 ng/ml). B, Wnt 7a and Wnt $7 \mathrm{~b}$ also increase EGFR expression in explants of E11.5 cortex cultured for $5 \mathrm{~d}$. C, Blocking Wnt signaling with $\mathrm{mFz} 8-\mathrm{Fc}(250 \mathrm{ng} / \mathrm{ml}$ per 2 explants) reduces the proportion of cells expressing a high level of EGFRs among control infected cells and cells infected with Wnt 7a virus. D, E, A Wnt 7a-infected cell expresses the viral marker $\beta$-gal $\left(D\right.$, arrow) and EGFRs ( $E$, arrow). ${ }^{*} p \leq 0.04$ comparing Wnt with control virus, or mFz8-Fc with lgG-Fc; ${ }^{* *} p<0.003$ comparing Wnt 7a plus BMP with Wnt 7a.

also greater among Wnt 7a-infected cells than control infected cells (Fig. 3A). This suggests that Wnts act like FGF2 to promote progenitor maturation to an EGF-responsive state (Lillien and Raphael, 2000). Unlike FGF2 and Shh (see below), however, Wnts did not induce EGF responsiveness prematurely but instead required an additional $1-2 \mathrm{~d}$ (data not shown). This was not because of additional time required for virally transduced Wnts to be produced and to act on progenitors, because proliferation was increased by Wnts 3-4 d after infection (Fig. 1). This discrepancy raised the possibility that Wnts did not modulate maturation directly but instead used secondary signals that promoted maturation.

Although stem cells have been identified by their ability to generate neurospheres, they are better characterized by selfrenewal (Reynolds and Weiss, 1992). To assess this property, neurospheres were passaged, and the proportion of infected cells that generated new neurospheres was determined as described previously (see Materials and Methods). Although Wnt 7a tended to increase the proportion of progenitors that generated secondary and tertiary neurospheres, this difference was not significant (Fig. 3B,C). Even after four passages, however, neurospheres from Wnt-infected cells generated neuronal and glial progeny (data not shown), indicating that the progenitor they 

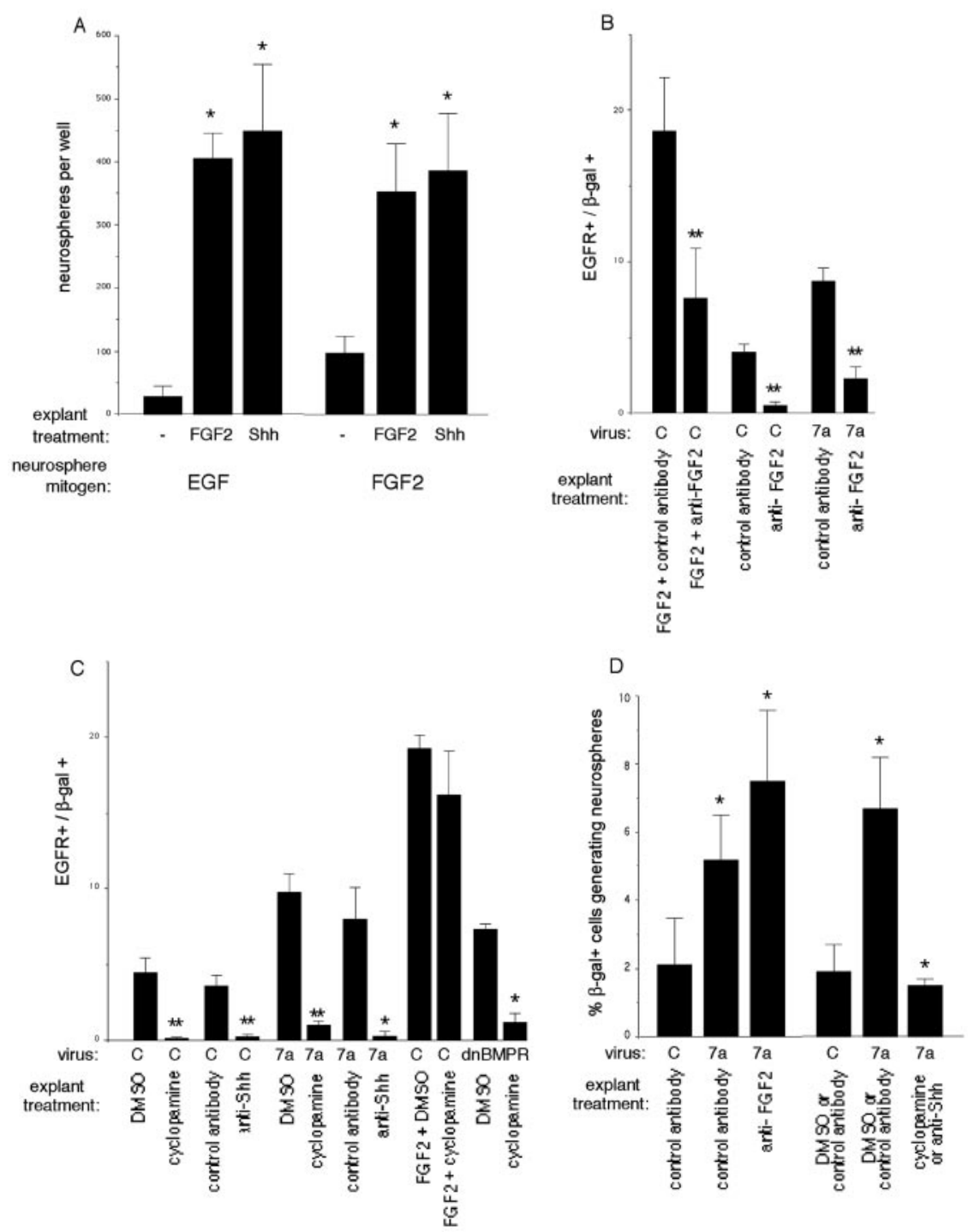

Figure 5. FGF2 and Shh mediate the effects of Wnt 7a on EGFR expression and primary neurospheres. A, Explants of E10.5 cortex were exposed to FGF2 $(10 \mathrm{ng} / \mathrm{ml})$ or Shh $(5 \mu \mathrm{g} / \mathrm{ml})$ for $2-3 \mathrm{~d}$, then dissociated and cultured in a neurosphere assay. These factors induce mitotic responsiveness to EGF prematurely and increase the number of neurosphere-forming cells when FGF2 is used as the neurosphere mitogen. B, EGFR expression is reduced by FGF2-neutralizing antibodies in control infected explants and explants infected with Wnt 7a virus. For these experiments, E10.5 explants were infected, treated for $4 \mathrm{~d}$ with control or FGF2neutralizing antibodies, then stained with $\beta$-gal and EGFR antibodies. C, Inhibiting signaling by endogenous Shh in explants of E11.5 cortex reduces expression of EGFRs among cells infected with control, Wnt 7a, or dnBMPR1B viruses. Explants were treated with cyclopamine (0.5-5 $\mu \mathrm{M}$ ) or Shh-neutralizing antibody (5E1, 1:5 to 1:4) for $4 \mathrm{~d}$ after infection, and EGFR expression was assessed as in B. DMSO or PAX6 hybridoma supernatant was used for control. D, The increase in primary neurospheres associated with Wnt $7 \mathrm{a}$ depends on Shh but not FGF2. FGF2 $(10 \mathrm{ng} / \mathrm{m})$ was used as the neurosphere mitogen. ${ }^{*} p<0.05$ relative to control treatment or control virus; ${ }^{* *} p<0.005$ relative to control treatment.

were derived from remained multipotent. Enhanced formation of neurospheres in primary but not subsequent Wnt-infected cultures could reflect downregulation of $\mathrm{Fz}$, as noted in vivo during late embryonic development (Kim et al., 2001b). Alternatively, this finding could indicate that Wnt requires additional signals to promote a "stem cell state" that are present in explants but not neurosphere cultures (see below) and/or that Wnts promote the development of multipotent, transit-amplifying progenitors.

\section{Wnts and BMPs modulate EGFR expression}

Progenitor maturation to an SVZ state is associated with an increase in expression of EGFRs among a subset of SVZ cells, con- ferring mitotic responsiveness to EGFfamily ligands (Burrows et al., 1997). Wnts enhanced the proportion of EGFresponsive progenitors in a neurosphere assay (Fig. 3), suggesting that they increased EGFR expression. To confirm this, E10.5-E11.5 cortical explants were infected with Wnt 7a or control virus then stained with an antibody to EGFRs $5 \mathrm{~d}$ later. The proportion of Wnt-infected cells that expressed a high level of EGFRs was approximately twofold greater than control infected cells (Fig. 4A,D,E). A similar effect on EGFRs was observed with Wnt 7b (Fig. 4B). The Wnt inhibitor mFz8-Fc (250 ng/ml per two explants) reduced expression of EGFRs among control infected cells and cells infected with Wnt 7a (Fig. $4 C$ ). These observations support the idea that endogenous Wnts promote progenitor maturation to an EGFR-positive SVZ state.

We reported previously that BMPs blocked progenitor maturation in part by antagonizing responses to FGF2, which promotes maturation (Lillien and $\mathrm{Ra}$ phael, 2000). BMP4 also inhibited Wnt7ainduced elevation of EGFRs (Fig. 4A). The similarities between FGF2 and Wnts, together with the results of blocking Wnt signaling, suggested that a Wnt family member could also be involved in promoting progenitor maturation, acting either independently of FGF2 or in a common pathway.

\section{Wnt interactions with FGF2 and Shh}

We have shown previously that FGF2 promoted EGFR expression and mitotic responsiveness to EGF prematurely in cultures of rat cortex (Lillien and Raphael, 2000). FGF2 had similar effects on mouse cortical progenitors (Fig. 5A,B). Shh also induced premature expression of EGFRs $(0 \pm 0 \%$ for untreated vs $5 \pm 1 \%$ for Shhtreated; $n=3 ; p=0.04)$ and mitotic responsiveness to EGF (Fig. 5A) in E10.5 mouse cortical explants.

Unlike FGF2 and Shh, Wnts did not induce premature expression of a high level of EGFRs but instead required an additional 1-2 d. One explanation for the delay could be that additional time was required for the mobilization of secondary signaling pathways that promote maturation. In other tissues, some effects of Wnts have been reported to depend on FGFs or Shh (Yang and Niswander, 1995; McGrew et al., 1997; Kengaku et al., 1998; Kawakami et al., 2001). To determine whether Wnt 7a requires FGF2 or Shh for its effects on cortical progenitors, explants (E10.5-E11.5) were treated with FGF2-neutralizing antibodies $(10-50 \mu \mathrm{g} / \mathrm{ml})$, cyclopamine $(0.5-5 \mu \mathrm{M})$ (Cooper et al., 1998), or a Shh-neutralizing antibody (5E1; 1:5 to 1:4) (Ericson et al., 1996) for $4 \mathrm{~d}$ after infection with Wnt $7 \mathrm{a}$ or control viruses. We then assayed EGFR expression, proliferation, and generation of primary neurospheres. 


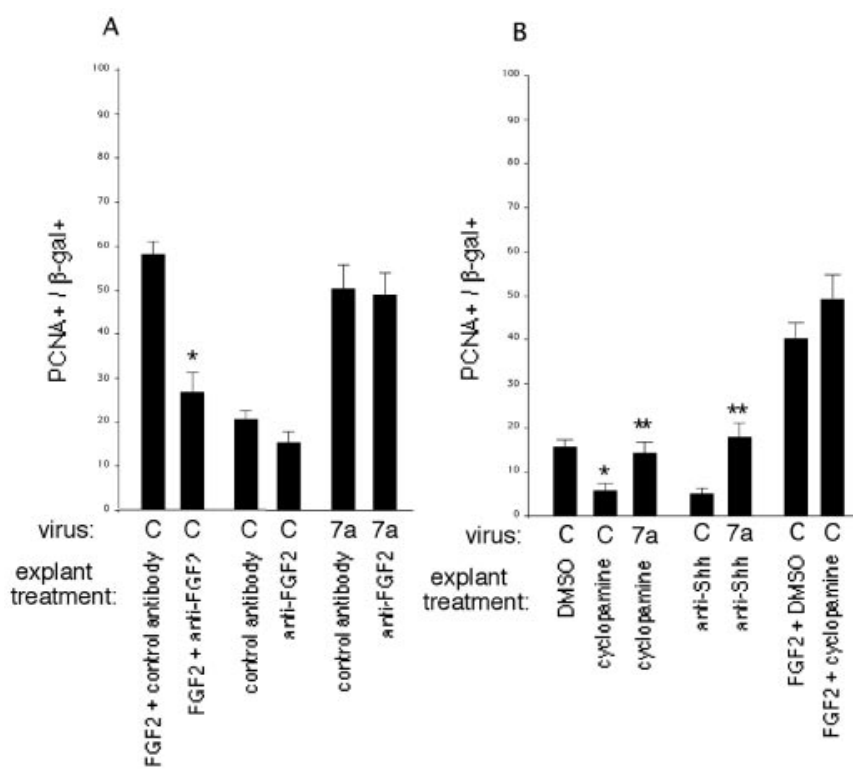

Figure 6. Wnt stimulates proliferation independently of FGF2 or Shh. A, Signaling by exogenous or endogenous FGF2 was inhibited with FGF2-neutralizing antibodies in explants of E10.5 cortex for $4 \mathrm{~d}$ after infection with either control or Wnt $7 \mathrm{a}$ virus. Mouse or rabbit Ig $\mathrm{G}$ was used for control. The proportion of infected ( $\beta$-gal-positive) cells that were dividing (PCNA-positive) was determined immunocytochemically. Note that FGF2-neutralizing antibodies reduce proliferation stimulated by exogenous FGF2 (10 ng/ml) but not by Wnt 7a. B, Signaling by Shh in explants of E11.5 cortex was inhibited with either cyclopamine $(0.5-5 \mu \mathrm{m})$ or a Shhneutralizing antibody (5E1, 1:5 to 1:4) 4 d after infection with either control or Wnt 7a virus. DMSO was used for control. Proliferation was assessed as in $A .{ }^{*} p \leq 0.03$ relative to control explants; ${ }^{* *} p \leq 0.003$ relative to control virus.

FGF2 neutralizing antibodies inhibited the normal developmental increase in EGFR expression among control infected cells (Fig. $5 B$ ), confirming a role for FGF2 in progenitor maturation suggested by our previous work. FGF2 neutralizing antibodies also inhibited the Wnt 7a-induced increase in EGFRs (Fig. 5B). Blocking Shh with cyclopamine or a neutralizing antibody inhibited the normal developmental increase in EGFRs, suggesting that endogenous Shh also contributes to the maturation of progenitors. Moreover, blocking Shh inhibited the Wnt-7a-induced increase in EGFRs (Fig. 5C). In contrast, cyclopamine did not block FGF2-induced expression of EGFRs (Fig. 5C). Maturation induced by Wnts therefore depends on FGF2 or Shh, but maturation induced by FGF2 does not depend on Shh.

Our previous work has shown that blocking endogenous BMP signaling with a dominant negative BMPR1B virus promoted progenitor maturation by a nonautonomous mechanism (Lillien and Raphael, 2000) (Fig. 5C). This finding suggested that BMP normally inhibited the expression or availability of a signal that promoted maturation. When Shh signaling was blocked in explants infected with dnBMPR1B virus, the maturationpromoting effect of dnBMPR1B was inhibited, indicating that it depends on Shh (Fig. 5C).

To determine whether proliferation stimulated by Wnt $7 \mathrm{a}$ also depends on other factors, FGF2 and Shh were blocked in Wntinfected explants. FGF2-neutralizing antibodies inhibited proliferation elicited by exogenous FGF2 (10 ng/ml) among control infected cells but did not reduce proliferation of Wnt $7 \mathrm{a}$-infected cells (Fig. 6A). Cyclopamine inhibited proliferation in explants infected with control virus (Fig. $6 B$ ), consistent with previous reports that Shh stimulates the proliferation of cortical progenitors (Rowitch et al., 1999; Dahmane et al., 2001). Although pro- liferation stimulated by Wnt 7a was reduced when Shh was blocked, Wnt still stimulated proliferation compared with control infected explants treated with cyclopamine or anti-Shh (Fig. $6 B)$. Proliferation stimulated by FGF2 was not reduced by cyclopamine (Fig. $6 B$ )

These data suggest that FGF2 or Shh mediates the effect of Wnt on progenitor maturation but not proliferation. To determine whether FGF2 or Shh mediates the effect of Wnts on neurosphere-forming cells, control or Wnt-infected explants were treated as described above to block FGF2 or Shh, then dissociated and cultured in FGF2 for $10 \mathrm{~d}$. After blocking of FGF2 in explants, the proportion of Wnt 7a-infected cells that generated neurospheres was still greater than control infected cells (Fig. $5 D)$. In contrast, after blocking of Shh in explants, the proportion of Wnt 7a-infected cells that formed primary neurospheres was reduced to levels seen among control infected, untreated cells (Fig. 5D). These observations suggest that the Wnt 7a-induced increase in primary neurospheres depends on Shh but not FGF2.

\section{Wnt 7a promotes SVZ fate in vivo}

In vitro studies suggest that Wnts promote the maturation of progenitors to an EGF-responsive state that is characteristic of a subset of SVZ progenitors. A better criterion for distinguishing SVZ progenitors more generally is laminar position in the cerebral wall. To determine whether Wnt 7a promotes the development of SVZ progenitors defined by this criterion, we infected progenitors in utero with a retrovirus that expresses Wnt 7a or with a control virus. The viruses were injected into the lateral ventricles of E14.5 or E10.5 mice. Three to $6 \mathrm{~d}$ later, the laminar distribution of the infected cells in the cortex was analyzed (see Materials and Methods).

When progenitors were infected at E14.5, we noted several differences in the distribution of control and Wnt-infected cells 3-4 d after infection. Wnt-infected cells tended to remain in germinal layers (Fig. 7A), consistent with increased proportions of BrdU-positive and PCNA-positive cells in vitro. In contrast, more control infected cells were located in the IZ. We did not see a difference in the proportion of Wnt-infected cells in the VZ. These observations suggest that Wnt 7a promotes an SVZ progenitor cell fate.

Infection at E14.5 might have been too late to reveal that Wnt 7 a can also promote a VZ progenitor fate. To address this possibility, we infected cortical progenitors at E10.5 and analyzed the distribution of their progeny $6 \mathrm{~d}$ later, at E16.5 (Fig. $7 B-F$ ). As observed for infections at E14.5, the proportion of infected cells in the SVZ was greater for Wnt 7a than control virus. In contrast, more control infected cells were located in the cortical plate (Fig. $7 B-E$ ). Thus, even when infections were initiated and analyzed earlier, Wnt 7a diverted progenitors to the SVZ instead of their normal fate as neurons in the cortical plate. These observations provide additional support for the idea that Wnt 7 a promotes the development of SVZ progenitors in the embryonic cortex.

\section{Discussion}

To further investigate the identity of signals that promote progenitor maturation to an SVZ state in the developing cortex, we tested Wnts by overexpression in vitro and in vivo. We also blocked signaling in vitro by Wnts and two other factors that can promote maturation, Shh and FGF2. Our findings suggest that Wnts, Shh, and FGF2 all contribute to progenitor maturation. Rather than acting independently, these factors appear to promote maturation through a common pathway. 

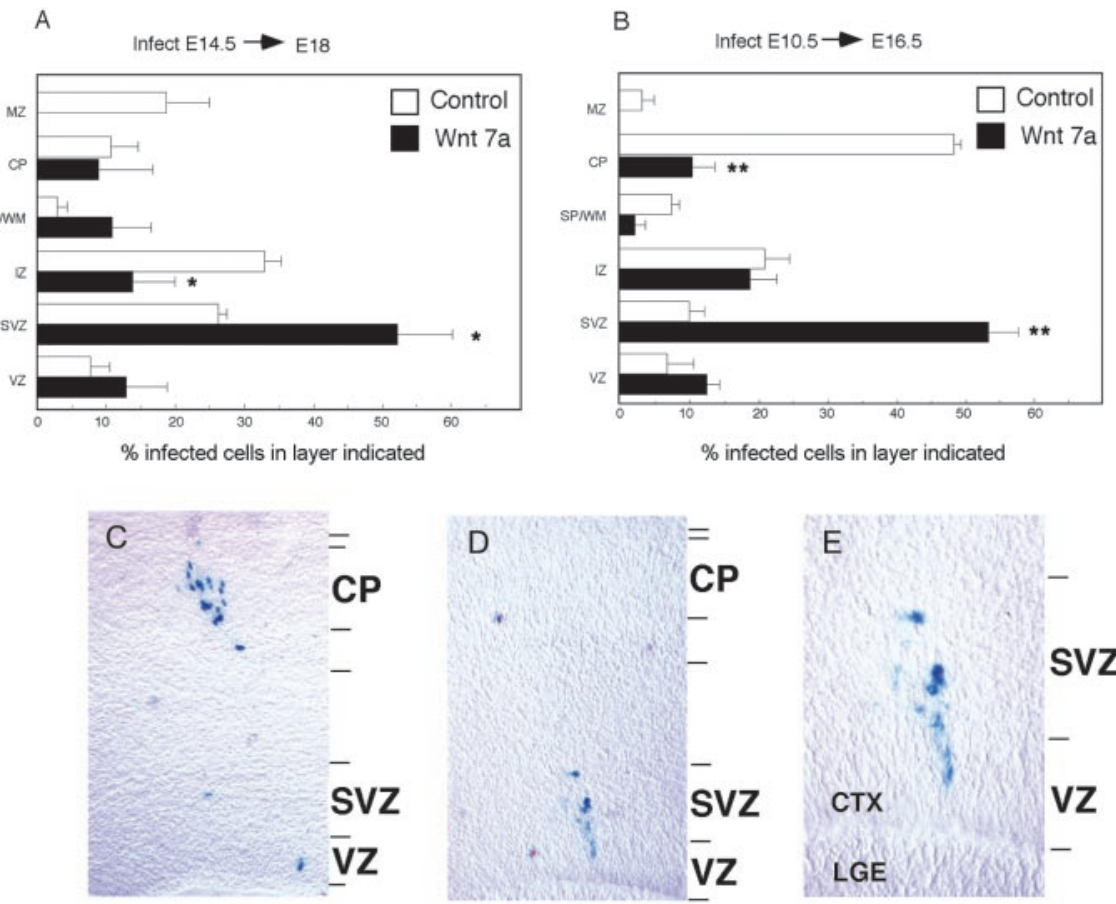

Figure 7. Wnt 7a infection in vivo promotes SVZ fate. $A$, Histogram of the laminar distribution of cells in the E18.5 cortex after infection with control or Wnt 7a virus at E14.5. B. Histogram of laminar distribution of cells in the E16.5 cortex after infection with control or Wnt 7a virus at E10.5. C $-E$, Micrographs of E16.5 dorsolateral cortex infected with control virus ( $C$ ) or Wnt 7a virus $(D$, $E)$ at E10.5. $E$, Higher magnification image of cells in $D$. Control infected E10.5 cells migrated to the cortical plate $(B, C)$, but cells infected with Wnt 7a virus tended to remain in the SVZ $(A, B, D, E)$. VZ, Ventricular zone; SVZ, subventricular zone; IZ, intermediate zone; SP/WM, subplate/white matter; $C P$, cortical plate; MZ, marginal zone; $C T X$, cortex; LGE, lateral ganglionic eminence. ${ }^{*} p=$ $0.04 ;{ }^{* *} p=0.01$ relative to control virus.

\section{Wnts promote $S V Z$ progenitor development}

Our previous work suggested that progenitor maturation to an EGF-responsive state characteristic of a subset of SVZ cells is regulated by extrinsic signals (Lillien and Raphael, 2000). Several observations in the present study suggest that a Wnt family member contributes to the VZ to SVZ transition. First, Wnt 7a and Wnt $7 \mathrm{~b}$ promoted expression of a high level of EGFRs that confers mitotic responsiveness to EGF. Second, blocking endogenous Wnt signaling inhibited the normal developmental increase in EGFRs. Third, overexpression of Wnt $7 \mathrm{a}$ in vivo with a retrovirus increased the proportion of infected cells in the SVZ. It remains to be determined whether these cells would have migrated to the cortical plate with longer survival times and what layers of the cortex they would occupy. It is also possible that these cells might remain in the SVZ with longer survival times, as noted after transplantation of SVZ-derived neurospheres (Ourednik et al., 2001). Many, although not all, progenitors in the SVZ express a high level of EGFRs (Seroogy et al., 1995; Eagleson et al., 1996; Burrows et al., 1997; Kornblum et al., 1997). The proportion of Wnt-infected cells that expressed a high level of EGFRs was smaller than the proportion of Wnt-infected cells found in the SVZ (compare Figs. 4 and 7). This suggests that Wnt signaling promotes the development of SVZ progenitors more generally.

The maturation of progenitors from VZ to SVZ can be distinguished initially at approximately E13 in the lateral cortex of mice (Miyama et al., 2001). Two Fz receptors, $\mathrm{mFz}-5$ and $\mathrm{mFz}-8$, are expressed at higher levels by progenitors in the lateral cortex at this time (Kim et al., 2001b), suggesting that their expression determines the temporal and spatial patterns of changes in pro- genitors induced by Wnts. Moreover, $\mathrm{mFz}-5$ mRNA is upregulated between E10.5 and E12.5 (Kim et al., 2001b). This precedes progenitor maturation by $1-2 \mathrm{~d}$, consistent with a role in the transduction of a maturation signal.

The cellular mechanism by which Wnts promote the development of SVZ progenitors is not known, although observations from our study suggest that additional extracellular signals are involved. Wnts stimulated proliferation in vitro, suggesting a proliferation-based mechanism. If the only function of Wnts was to stimulate proliferation, however, it is not clear why Wnt-infected E10.5 progenitors partitioned into the SVZ rather than remaining in the VZ. Moreover, Wnts stimulated proliferation but not maturation when FGF2 or Shh signaling was blocked, and the Wnt inhibitor $\mathrm{mFz} 8-\mathrm{Fc}$ reduced EGFR expression without inhibiting proliferation, supporting the idea that proliferation alone does not regulate progenitor maturation. Our previous work with FGF2 and BMPs also argued against a proliferationbased mechanism (Lillien and Raphael, 2000). Wnts did not significantly alter survival in E10.5-E11.5 explants cultured for 5-6 d (for example, $2.3 \pm 0.9 \%$ of control infected cells expressed activated caspase-3, compared with $1.8 \pm 0.5 \%$ of Wnt-infected cells; $n=4 ; p=0.7)$. Instead, Wnts in combination with Shh or FGF2 could alter progenitor properties in an instructive manner.

\section{Wnt 7a stimulates proliferation of neurogenic cells}

Wnt 7a is expressed much earlier than the time the SVZ develops, suggesting that it could have distinct effects on early embryonic progenitors. Wnts stimulated the proliferation of early cortical progenitors, reversibly inhibiting their differentiation into neurons without inducing astrocytes or oligodendrocytes. Wnt 7a could therefore act as a mitogen for neuron-restricted or multipotent progenitor cells, as could Wnt 7b. Wnt 7a was mitogenic only before E17, consistent with the timing of Fz expression (Kim et al., 2001b). Wnts may therefore play a role in the timing of cell-cycle withdrawal and neuronal differentiation before E17, in addition to their effect on progenitor maturation. Failure of the Wnt inhibitor mFz8-Fc to reduce proliferation could indicate that other mitogens can substitute for Wnts in the cortex.

\section{Shh promotes progenitor maturation}

Our previous work suggested that BMPs were negative regulators of progenitor maturation, acting in part by antagonizing responses to signals that promote maturation. BMPs interact antagonistically with a number of extrinsic signals, including Shh (Penton and Hoffman, 1996; Neubuser et al., 1997; Zhu et al., 1999). In Drosophila, Hh induces expression of EGFRs (Huang et al., 1998). Several observations support the idea that Shh promotes the maturation of cortical progenitors. First, exogenous Shh increased EGFR expression and responsiveness prematurely. Second, blocking Shh signaling in explants inhibited the normal developmental increase in EGFR expression. Third, maturation 
induced by inhibiting BMP signaling with a $\operatorname{dnBMPR} 1 \mathrm{~B}$ virus was inhibited if Shh was blocked. In a previous study, we noted that recombinant Shh did not induce premature changes in EGFR expression and signaling (Lillien and Raphael, 2000). The highest concentration of Shh tested previously was $0.5 \mu \mathrm{g} / \mathrm{ml}$. In the present study, we found that a higher concentration of Shh (5 $\mu \mathrm{g} / \mathrm{ml}$ ) was needed to see an effect on progenitor maturation. Although this seems too high to be physiological, it should be noted that we used unmodified Shh-N terminal peptide, which is $\sim 150$-fold less active than modified Shh (Taylor et al., 2001). It has been reported that Shh can be expressed ectopically in cortical explants (Tekki-Kessaris et al., 2001); however, Shh was shown recently to be expressed in the embryonic cortex by at least E14 (Dahmane et al., 2001). Although we cannot rule out the possibility that our explants also express Shh ectopically, it is likely that cortical progenitors are normally exposed to Shh at the time the SVZ is generated.

\section{Dissecting Wnt interactions with BMP4, FGF2, and Shh}

Our data suggest that Wnts influence several behaviors of cortical progenitors, including the transition from VZ to SVZ and proliferation. We do not know yet which intracellular Wnt pathway(s) mediates these responses. In other systems, some responses to Wnts depend on heterologous factors, including FGF2 and Shh (Yang and Niswander, 1995; McGrew et al., 1997; Kengaku et al., 1998; Domingos et al., 2001; Kawakami et al., 2001). Blocking FGF2 or Shh in Wnt-infected cortical progenitors revealed that some of their responses to Wnts also depended on these molecules. For example, the effect of Wnt on progenitor maturation depended on FGF2 or Shh, but Wnt still stimulated proliferation when FGF2 or Shh was inhibited. Wnts also promoted the formation of primary neurospheres. This depended on signaling by Shh but not FGF2 during the period in explant culture. Shh is made in explants but not in neurospheres (Zhu et al., 1999), and this could explain why Wnt 7a did not promote the generation of neurospheres beyond the primary cultures. Although Wnts depend on Shh or FGF2 for some effects, we do not know whether Wnts regulate the expression or availability of FGF2 and Shh or whether they modulate progenitor responsiveness to these molecules. It is also not clear whether previous or concomitant Wnt signaling is required for responses to FGF2 or Shh.

In a previous study, we showed that BMP signaling inhibited maturation of cortical progenitors by two mechanisms (Lillien and Raphael, 2000). First, BMPs antagonized maturation induced by FGF2. In the present study, we show that BMP4 also antagonized the effect of Wnt 7a on progenitor maturation. We have also shown previously that BMPs negatively regulated expression or availability of a signal that promoted maturation (Lillien and Raphael, 2000). Here, we show that maturation promoted by blocking BMP signaling with a dnBMPR1B virus depends on Shh. It remains to be determined whether this reflects direct regulation of Shh signaling by BMP and/or indirect regulation via Wnt.

By overexpressing Wnts with retroviruses, we intended to saturate the Wnt inhibitors expressed in the developing cortex (Kim et al., 2001a,b). Although this strategy revealed several functions of Wnts, it is not clear whether the endogenous ligand is Wnt 7a or $7 \mathrm{~b}$. Wnt $7 \mathrm{~b}$ is expressed by deep-layer neurons in the cortical plate at least as early as E13.5 (Rubenstein et al., 1999; Kim et al., 2001a). If a feedback mechanism contributes to the normal sequence of events, Wnt $7 \mathrm{~b}$ made by deep-layer neurons could signal back to $\mathrm{VZ}$ progenitor cells to promote their maturation to an SVZ state, leading to the production of upper-layer neurons
(Tarabykin et al., 2001) and glia. Shh is available to embryonic cortical progenitors (Dahmane et al., 2001), FGF2 is expressed in germinal layers of the cortex (Vaccarino et al., 1999), and progenitors express receptors for Shh, FGF2, Wnts, and BMPs (Zhang et al., 1998; Vaccarino et al., 1999; Zhu et al., 1999; Dahmane et al., 2001). What remains to be clarified are the mechanisms by which these signals interact to generate temporally and spatially regulated changes in progenitors.

\section{References}

Austin TW, Solar GP, Ziegler FC, Liem L, Matthews W (1997) A role for the Wnt gene family in hematopoiesis: expansion of multilineage progenitor cells. Blood 89:3624-3635.

Bottenstein JE, Sato GH (1979) Growth of a rat neuroblastoma cell line in serum-free supplemented medium. Proc Natl Acad Sci USA 76:514-517.

Boulder Committee (1970) Embryonic vertebrate central nervous system: revised terminology. Anat Rec 166:257-261.

Burrows RC, Wancio D, Levitt P, Lillien L (1997) Response diversity and the timing of progenitor cell maturation are regulated by developmental changes in EGFR expression in the cortex. Neuron 19:251-267.

Caric D, Raphael H, Viti J, Feathers A, Wancio D, Lillien L (2001) EGFRs mediate chemotactic migration in the developing telencephalon. Development 128:4203-4216.

Cepko CL, Ryder EF, Austin CP, Walsh C, Fekete DM (1993) Lineage analysis using retrovirus vectors. Methods Enzymol 225:933-960.

Cooper MK, Porter JA, Young KE, Beachy PA (1998) Teratogen-mediated inhibition of target tissue response to Shh signaling. Science 280:1603-1607.

Dahmane N, Sanchez P, Gitton Y, Palma V, Sun T, Beyna M, Weiner H, Ruiz i Altaba A (2001) The sonic hedgehog-Gli pathway regulates dorsal brain growth and tumorigenesis. Development 128:5201-5212.

Domingos PM, Itasaki N, Jones CM, Mercurio S, Sargent MG, Smith JC, Krumlauf R (2001) The Wnt/beta-catenin pathway posteriorizes neural tissue in Xenopus by an indirect mechanism requiring FGF signalling. Dev Biol 239:148-160.

Eagleson KL, Ferri RT, Levitt P (1996) Complementary distribution of collagen type IV and the epidermal growth factor receptor in the embryonic rat telencephalon. Cereb Cortex 6:540-549.

Ericson J, Morton S, Kawakami A, Roelink H, Jessell TM (1996) Two critical periods of sonic hedgehog signaling required for the specification of motor neuron identity. Cell 87:661-673.

Friedrich G, Soriano P (1991) Promoter traps in embryonic stem cells: a genetic screen to identify and mutate developmental genes in mice. Genes Dev 5:1513-1523.

Fukuchi-Shimogori T, Grove EA (2001) Neocortex patterning by the secreted signaling molecule FGF8. Science 294:1071-1074.

Grove EA, Tole S, Limon J, Yip L, Ragsdale CW (1998) The hem of the embryonic cerebral cortex is defined by the expression of multiple Wnt genes and is compromised in Gli3-deficient mice. Development 125:2315-2325.

Haydar TF, Wang F, Schwartz ML, Rakic P (2000) Differential modulation of proliferation in the neocortical ventricular and subventricular zones. J Neurosci 20:5764-5774.

Huang Z, Shilo BZ, Kunes S (1998) A retinal axon fascicle uses spitz, an EGF receptor ligand, to construct a synaptic cartridge in the brain of Drosophila. Cell 95:693-703.

Kawakami Y, Capdevila J, Buscher D, Itoh T, Rodriguez Esteban C, Izpisua Belmonte JC (2001) WNT signals control FGF-dependent limb initiation and AER induction in the chick embryo. Cell 104:891-900.

Kengaku M, Capdevila J, Rodriguez-Esteban C, De La Pena J, Johnson RL, Belmonte JC, Tabin CJ (1998) Distinct WNT pathways regulating AER formation and dorsoventral polarity in the chick limb bud. Science 280:1274-1277.

Kim AS, Anderson SA, Rubenstein JL, Lowenstein DH, Pleasure SJ (2001a) Pax-6 regulates expression of SFRP-2 and Wnt-7b in the developing CNS. J Neurosci 21:RC132(1-5).

Kim AS, Lowenstein DH, Pleasure SJ (2001b) Wnt receptors and Wnt inhibitors are expressed in gradients in the developing telencephalon. Mech Dev 103:167-172.

Korinek V, Barker N, Moerer P, van Donselaar E, Huls G, Peters PJ, Clevers H (1998) Depletion of epithelial stem-cell compartments in the small intestine of mice lacking Tcf-4. Nat Genet 19:379-383. 
Kornblum HI, Hussain RJ, Bronstein JM, Gall CM, Lee DC, Seroogy KB (1997) Prenatal ontogeny of the epidermal growth factor receptor and its ligand, transforming growth factor alpha, in rat brain. J Comp Neurol 380:243-261.

Lee SM, Tole S, Grove E, McMahon AP (2000) A local Wnt-3a signal is required for development of the mammalian hippocampus. Development 127:457-467.

Lillien L (1995) Changes in retinal cell fate induced by overexpression of EGF receptor. Nature 377:158-162.

Lillien L, Raphael H (2000) BMP and FGF regulate the development of EGFresponsive neural progenitor cells. Development 127:4993-5005.

McGrew LL, Hoppler S, Moon RT (1997) Wnt and FGF pathways cooperatively pattern anteroposterior neural ectoderm in Xenopus. Mech Dev 69:105-114.

Megason SG, McMahon AP (2002) A mitogen gradient of dorsal midline Wnts organizes growth in the CNS. Development 129:2087-2098.

Miyama S, Takahashi T, Goto T, Bhide PG, Caviness Jr VS (2001) Continuity with ganglionic eminence modulates interkinetic nuclear migration in the neocortical pseudostratified ventricular epithelium. Exp Neurol 169:486-495.

Neubuser A, Peters H, Balling R, Martin GR (1997) Antagonistic interactions between FGF and BMP signaling pathways: a mechanism for positioning the sites of tooth formation. Cell 90:247-255.

Olsson M, Campbell K, Turnbull DH (1997) Specification of mouse telencephalic and mid-hindbrain progenitors following heterotopic ultrasound-guided embryonic transplantation. Neuron 19:761-772.

Ourednik V, Ourednik J, Flax JD, Zawada WM, Hutt C, Yang C, Park KI, Kim SU, Sidman RL, Freed CR, Snyder EY (2001) Segregation of human neural stem cells in the developing primate forebrain. Science 293:1820-1824.

Penton A, Hoffmann FM (1996) Decapentaplegic restricts the domain of wingless during Drosophila limb patterning. Nature 382:162-164.

Reynolds BA, Weiss S (1992) Generation of neurons and astrocytes from isolated cells of the adult mammalian central nervous system. Science 255:1707-1710.

Rowitch DH, S-Jacques B, Lee SM, Flax JD, Snyder EY, McMahon AP (1999) Sonic hedgehog regulates proliferation and inhibits differentiation of CNS precursor cells. J Neurosci 19:8954-8965.

Rubenstein JL, Anderson S, Shi L, Miyashita-Lin E, Bulfone A, Hevner R (1999) Genetic control of cortical regionalization and connectivity. Cereb Cortex 9:524-532.
Seroogy KB, Gall CM, Lee DC, Kornblum HI (1995) Proliferative zones of postnatal rat brain express epidermal growth factor receptor mRNA. Brain Res 670:157-164.

Takahashi T, Nowakowski RS, Caviness Jr VS (1995) Early ontogeny of the secondary proliferative population of the embryonic murine cerebral wall. J Neurosci 15:6058-6068.

Tarabykin V, Stoykova A, Usman N, Gruss P (2001) Cortical upper layer neurons derive from the subventricular zone as indicated by Svet1 gene expression. Development 128:1983-1993.

Taylor FR, Wen D, Garber EA, Carmillo AN, Baker DP, Arduini RM, Williams KP, Weinreb PH, Rayhorn P, Hronowski X, Whitty A, Day ES, Boriack-Sjodin A, Shapiro RI, Galdes A, Pepinsky RB (2001) Enhanced potency of human sonic hedgehog by hydrophobic modification. Biochemistry 40:4359-4371.

Tekki-Kessaris N, Woodruff R, Hall AC, Gaffield W, Kimura S, Stiles CD, Rowitch DH, Richardson WD (2001) Hedgehog-dependent oligodendrocyte lineage specification in the telencephalon. Development 128:2545-2554.

ten Dijke P, Yamashita H, Sampath TK, Reddi AH, Estevez M, Riddle DL, Ichijo H, Heldin CH, Miyazono K (1994) Identification of type I receptors for osteogenic protein-1 and bone morphogenetic protein-4. J Biol Chem 269:16985-16988.

Theiler K (1972) The house mouse. New York: Springer.

Vaccarino FM, Schwartz ML, Raballo R, Nilsen J, Rhee J, Zhou M, Doetschman T, Coffin JD, Wyland JJ, Hung YT (1999) Changes in cerebral cortex size are governed by fibroblast growth factor during embryogenesis. Nat Neurosci 2:246-253.

Wodarz A, Nusse R (1998) Mechanisms of Wnt signaling in development. Annu Rev Cell Dev Biol 14:59-88.

Yang Y, Niswander L (1995) Interaction between the signaling molecules WNT7a and SHH during vertebrate limb development: dorsal signals regulate anteroposterior patterning. Cell 80:939-947.

Zhang D, Mehler MF, Song Q, Kessler JA (1998) Development of bone morphogenetic protein receptors in the nervous system and possible roles in regulating trkC expression. J Neurosci 18:3314-3326.

Zhu G, Mehler MF, Zhao J, Yung S, Kessler JA (1999) Sonic hedgehog and BMP2 exert opposing actions on proliferation and differentiation of embryonic neural progenitor cells. Dev Biol 215:118-129.

Zou H, Niswander L (1996) Requirement for BMP signaling in interdigital apoptosis and scale formation. Science 272:738-741. 